\title{
Peran penyuluh peternakan dalam peningkatan pendapatan anggota kelompok peternak babi di Kecamatan Tompaso Barat Kabupaten Minahasa
}

\author{
Y. Kogoya, G. D Lenzun*, E. Wantasen \\ Fakultas Peternakan Universitas Sam Ratulangi Manado, 95115 \\ Korespondensi (correspoding author) Email :_gamdicky@yahoo.com
}

\begin{abstract}
ABSTRAK
Penelitian ini bertujuan untuk melihat bagaimana tanggapan peternak terhadap peran penyuluh dalam peningkatan pendapatan usaha ternak babi di Desa Kamanga Kecamatan Tompaso Barat Kabupaten Minahasa. Sumber data yaitu data primer dan data sekunder. Metode pengumpulan data observasi dan wawancara. Populasi peternak yang memelihara ternak babi dan jumlah sampel yang di ambil yaitu anggota kelompok usaha ternak babi Desa Kamanga yang sudah mendapat pembinaan dari penyuluh Dinas Pertanian Peternakan dan Perkebunan Kabupaten Minahasa sebanyak 40 peternak. Hasil penelitian menunjukkan bahwa penyuluh dari dinas pertanian peternakan dan perkebunan memiliki peranan yang sangat besar dalam peningkatan pendapatan anggota kelompok peternak babi di Desa Kamanga Kecamatan Tompaso Kabupaten Minahasa. Program pembinaan kelompok peternak babi yang dikembangkan oleh penyuluh dari dinas pertanian peternakan dan perkebunan mendapat respon yang baik dari peternak karena penyuluhan telah memberikan peningkatan pendapatan pada peterbak babi di Desa Kamanga Kecamatan Tompaso Barat.
\end{abstract}

Kata kunci : Peran penyuluh, peningkatan pendapatan, peternak babi

\begin{abstract}
THE ROLE OF ANIMAL HUSBANDRY EXTENSION IN INCREASING INCOME OF PIG FARMER GROUP IN WEST TOMPASO DISTRICT, MINAHASA REGENCY. This study aims to see how the responses of farmers to the role ofextension workers in increasing the income of pig farming in Kamanga Village, West Tompaso District, Minahasa Regency. The data sources are primary and secondary. Observation and interview data collection methods. The population of breeders who raise pigs and the number of samples taken are members of the Kamanga Village hog farming group who have received guidance from the Minahasa District Agriculture, Animal Husbandry and Plantation Agency. Result study showed that extension officer from the agricultur and livestock service have a major role in increasing of income of pigs breeders in Kamanga village, Tompaso Sub District
\end{abstract}

Key words: Role of extension officer, income, pig breeders 


\section{PENDAHULUAN}

Pembinaan kelompok peternak babi melalui penyuluh merupakan solusi yang tepat untuk menjawab permasalahan kekurangan pemenuhan permintaan kebutuhan daging (Anwas, 2013.). Penyuluhan merupakan sebuah intervensi sosial yang melibatkan penggunaan komunikasi informasi secara sadar untuk membantu masyarakat membentuk pendapat mereka sendiri dan mengambil keputusan dengan baik. Pembinaan kelompok peternak babi dapat diusahakan dengan cara yang lebih baik dapat memberikan manfaat lebih berarti bagi petani yang mengusahakannya. Oleh karena itu pembangunan peternakan di Kabupaten Minahasa, khususnya pembinaan kelompok peternak babi perlu diarahkan, agar dapat menghasilkan suatu produk unggulan, juga ketersediaan ternak secara berkesinambungan.

Menurut Sapar., et al. (2012.) penyuluhan pertanian adalah proses pembelajaran bagi pelaku utama, dan pelaku usaha agar mereka mau dan mampu menolong dan mengorganisasikan dirinya dalam mengakses pasar, teknologi, permodalan dan sumber daya lainnya. Penyuluhan merupakan sarana kebijaksanaan yang dapat digunakan pemerintah untuk mendorong pembangunan pertanian. Di lain pihak, petani mempunyai kebebasan untuk menerima atau menolak saran yang diberikan penyuluh. Dengan demikian penyuluhan hanya dapat mencapai sasarannya jika perubahan yang diinginkan sesuai dengan kepentingan petani (Harinta., 2011.).

Dali et al. (2017) menjelaskan bahwa Populasi ternak babi di Kabupaten
Minahasa mengalami peningkatan dari tahun ke tahun, hal ini menunjukkan bahwa pembangunan peternakan di masa yang akan datang mempunyai prospek yang sangat cerah. Kabupaten Minahasa diarahkan, agar dapat menghasilkan suatu produk unggulan, dan juga ketersediaan ternak secara berkesinambungan, oleh karena itu peranan Dinas Pertanian Peternakan dan Perkebunan dalam membina dan memotivasi masyarakat khususnya kelompok peternak untuk lebih maju mengelola ternak secara baik dan berkelanjutan, agar berdampak pada terciptanya kelompok peternak yang maju dan mandiri serta peningkatan pendapatan usaha ternak (.Abdullah, dan Ibrahim, 2014; Nurfitri, 2018; Mandasai, 2014).. Jumlah kelompok peternak yang dibina pemerintah Kabupaten Minahasa sebanyak 84 kelompok peternak babi yang tersebar diseluruh wilayah Kabupaten Minahasa. Salah satu daerah Kabupaten Minahasa yang dijadikan sebagai pembinaan kelompok peternak babi adalah Desa Kamanga Kecamatan Tompaso Kabupaten Minahasa. Data Dinas Pertanian Peternakan dan Perkebunan Kabupaten Minahasa, bahwa jumlah populasi ternak babi di Kabupaten Minahasa pada tahun 2011 adalah 9.474 ekor, pada tahun 201211.676 ekor, pada tahun 201311.982 ekor, pada tahun 2014 17.384 ekor, sedangkan pada tahun 2015 ada 21.016 ekor. Rencana strategi Direktorat Jendral Peternakan dan Kesehatan Hewan untuk tahun 2010-2014, adalah peningkatan populasi ternak babi baik itu ternak babi lokal maupun babi eks impor sebesar 1,15\% setiap tahunnya, sehingga jumlah populasi babi di Indonesia mencapai 7.204.768 ekor dan menghasilkan daging sebesar 247.420 ton (Ditjen Peternakan, 2010) 


\section{METODE PENELITIAN}

\section{Waktu dan tempat}

Penelitian ini dilaksanakan pada Bulan Oktober - November Tahun 2019 di Desa Kamanga Kecamatan Tompaso Kabupaten Minahasa. Lokasi dipilih secara sengaja dengan pertimbangan bahwa pada lokasi tersebut telah dikembangkan pembinaan "Gapoktan (Gabungan Kelompok Tani)" oleh Dinas Pertanian Peternakan Dan Perkebunan Kabupaten Minahasa.

\section{Populasi dan Sampel}

Populasi di lokasi penelitian adalah semua peternak babi yang terdapat di Desa Kamanga Kecamatan Tompaso Kabupaten Minahasa sebanyak 40 peternak yang telah dibina oleh penyuluh Dinas Pertanian Peternakan Dan Perkebunan Kabupaten Minahasa selama \pm 5 tahun, karena sedikitnya jumlah populasi maka seluruh populasi sebanyak 40 peternak dijadikan sampel.

\section{Jenis dan sumber data}

jenis Data dalam penelitian ini adalah data kualitatif dan kuantitatif. data kualitatif adalah data yang bukan merupakan bilangan, atau bisa diartikan data berupa ciri-ciri, sifat-sifat, keadaan, atau gambaran dari kualitas objek yang diteliti. dan data kuantitatif adalah data yang berupa bilangan, nilainya bisa berubah-ubah atau bersifat variatif.

Sedangkan sumber data yang digunakan dalam penelitian ini adalah:

Data Primer yaitu data yang diperoleh dari hasil observasi melalui wawancara langsung dan juga melalui bantuan daftar kuesioner. dan Data Sekunder yaitu data yang diperoleh dari desa, kecamatan yang terkait atau berhubungan dengan penelitian ini. Data dikumpulkan dari hasil survei dengan menggunakan kuesioner dan ditambah dengan pengamatan/observasi lapangan. Data yang telah terkumpul kemudian ditabulasi untuk mendapatkan data-data riil yang digunakan untuk keperluan analisis.

\section{Metode analisis data}

Analisis yang digunakan adalah analisis deskriptif yaitu untuk menggambarkan fenomena atau kejadian dimana data yang diperoleh dilakukan dengan wawancara mendalam terhadap informan kunci serta dilihat dari data perencanaan dan laporan penyuluh dalam mendampingi kelompok selama tahun 2019.

Untuk mengetahui tanggapan atau respon peternak terhadap pembinaan kelompok peternak babi yang dilakukan oleh penyuluh Dinas Pertanian Peternakan Dan Perkebunan di Desa Kamanga Kecamatan Tompaso digunakan skala Likert dengan 5 alternatif jawaban dengan kriteria penilaian jika:

Responden menjawab A $=5$

Responden menjawab B $=4$

Responden menjawab $\mathrm{C}=3$

Responden menjawab $\mathrm{D}=2$

Responden menjawab E = 1

\section{HASIL DAN PEMBAHASAN}

\section{Letak wilayah dan geografis daerah penelitian}

Secara geografis Kabupaten Minahasa terletak di bagian timur Provinsi Sulawesi Utara. Kabupaten Minahasa memiliki luas wilayah yang relatif luas, secara astronomis terletak $5^{\circ} 2{ }^{\prime} 56^{\prime \prime}-5^{\circ} 21^{\prime}$ 16" Lintang selatan (LS) dan antara $119^{\circ} 56$ $30^{\circ}-120^{\circ} 25^{\prime} 33^{\prime \prime}$ Bujur timur (BT) yang berada di pantai timur bagian selatan Provinsi Sulawesi Utara. Luas wilayah Kecamatan Tompaso adalah $3.020 \mathrm{Ha}$, dengan jarak tempuh $15 \mathrm{Km}$ ke Ibukota Kabupaten Minahasa, dan $60 \mathrm{Km}$ ke ibukota Provinsi Sulawesi Utara, Manado. Kecamatan Tompaso terbagi 10 Desa. 
Kedudukan ibukota Kecamatan Tompaso terletak di desa Liba. Secara geografis Kecamatan Tompaso terletak antara: $12^{\circ}$ sampai $15^{\circ}$ lintang utara dan $46^{\circ}$ sampai $124^{\circ}$ bujur timur, dengan keadaan topografi datar. Ikbal, et al. (2014). Jelaskan bahwa Berada pada ketinggian 425 meter di atas permukaan laut, dengan batas-batas wilayah sebagai berikut :

Utara : Kecamatan Tompaso Barat

Timur : Kecamatan Langowan Timur dan Kecamatan Langowan Barat, serta Kecamatan Kakas Barat.

Selatan : kecamatan Langowan Utara

Barat : Kecamatan Tompaso Barat dan Kecamatan Kawangkoan

\section{Identitas dan karateristik responden}

Umur, pendidikan, luas lahan, status pemilikan lahan, jumlah Anggota keluarga, dan kehadiran dalam rapat kelompok tani/ternak. dapat dilihat pada Tabel 1 .

Tabel 1. Identitas dan Karateristik Responden.

\begin{tabular}{|c|c|c|c|}
\hline No & Keterangan & Jumlah (orang) & Persentase (\%) \\
\hline \multirow[t]{4}{*}{1} & Umur ( Tahun) & & \\
\hline & $<30$ & 12 & 16 \\
\hline & b. $\quad 30-50$ & 18 & 64 \\
\hline & c. $\quad>50$ & 10 & 20 \\
\hline \multirow[t]{4}{*}{2} & Pendidikan & & \\
\hline & a. SD & 10 & 27 \\
\hline & b. SLTP & 12 & 30 \\
\hline & c. SLTA & 18 & 37 \\
\hline \multirow[t]{4}{*}{3} & Luas lahan & & \\
\hline & a. $\quad 0,10-0,30$ ha & 6 & $3 \%$ \\
\hline & b. $\quad 0,31-0,50$ ha & 23 & $67 \%$ \\
\hline & c. $\quad 0,51-1$ ha & 11 & $30 \%$ \\
\hline \multirow[t]{3}{*}{4} & Status kepemilikan lahan & & \\
\hline & Milik sendiri & 31 & $87 \%$ \\
\hline & b. Sewa dan milik sendiri & 9 & $13 \%$ \\
\hline \multirow[t]{4}{*}{5} & Jumlah Anggota Keluarga & & \\
\hline & a. $\quad 1-3$ & 15 & $33 \%$ \\
\hline & b. $4-6$ & 17 & $47 \%$ \\
\hline & c. Lebih dari 6 & 8 & $20 \%$ \\
\hline \multirow[t]{4}{*}{6} & Kehadiran dalam rapat kelompok & & \\
\hline & a. $\quad<3 \mathrm{kali}$ & 5 & $17 \%$ \\
\hline & b. $\quad 3-5$ kali & 15 & $33 \%$ \\
\hline & c. 8 kali & 20 & $50 \%$ \\
\hline
\end{tabular}


Tabel 2. Tanggapan Peternak terhadap Penyuluh dalam Pembinaan Anggota Kelompok Peternak Babi.

\begin{tabular}{lcll}
\hline No. & Responden & Kualitatif & Kuantitatif \\
\hline 1. & 34 & Sangat mengetahui & 5 \\
2. & 6 & Mengetahui & 4 \\
3. & - & Cukup mengetahui & 3 \\
4. & - & Tidak mengetahui & 2 \\
5. & - & Sangat Tidak mengetahui & 1
\end{tabular}

Jumlah 40

Dari Tabel 2 menggambarkan bahwa responden mengetahui pengaruh penyuluh dalam pembinaan kelompok peternak babi yang dilakukan oleh penyuluh Dinas Pertanian Peternakan Dan Perkebunan diperoleh 34 responden yang sangat mengetahui dan 6 responden yang mengetahui. Hal ini menunjukkan bahwa peternak babi mengetahui dengan baik tujuan pembinaan kelompok peternak babi yang dilakukan oleh penyuluh dinas Pertanian Peternakan Dan Perkebunan Kabupaten Minahasa (Mutmainah, et al,. 2014).

Menurut Chamdi. (2011.) bahwa Didalam kegiatan penyuluh diharapkan program-program yang disampaikan hendaknya sesuai dengan permasalahan yang dihadapi oleh petani atau sesuai dengan kebutuhannya. Karena itu dibentuk kerjasama yang baik antara pihak pemerintah atau pihak penyampai program dengan pihak yang menerima program atau petani/peternak dalam menstransfer ilmuilmu teknologi baru untuk meningkatkan produksi usaha tani. Sudarsono, dan Suharsono (2016) menjelaskan bahwa untuk mengetahui tanggapan peternak terhadap pembinaan kelompok peternak babi yang dilakukan oleh Penyuluh Dinas Pertanian Peternakan Dan Perkebunan di Desa Kamanga Kecamatan Tompaso Kabupaten Minahasa. Menurut Talibo, et al (2017.) menjelaskan bahwa hasil yang diperoleh tentang tanggapan atau respon peternak terhadap pembinaan kelompok peternak babi menggambarkan bahwa, kerjasama antara penyuluh dinas Pertanian Peternakan Dan Perkebunan sebagai motivator, pendamping dan fasilitator dalam memberikan bantuan, materi dan arahan terjalin kerjasama yang baik dengan peternak sebagai penerima. Program pembinaan kelompok peternak babi yang dikembangkan penyuluh Dinas Pertanian Peternakan Dan Perkebunan mendapat respon yang baik dari peternak. Oleh karena itu, peternak mendapatkan manfaat yang besar baik dari segi pengetahuan, wawasan, perubahan perilaku untuk lebih maju dan berkembang dalam menerima inovasi (Astuti, (2011). Peternak sangat tertarik dengan manfaat penyuluhan khususnya berkaitan dengan materi perubahan teknologi peternakan dimana 100 persen mereka sangat berkeiginan apabila penyuluhan dilakukan sekali sebulan (Tabel 3). 
Tabel 3. Tanggapan Peternak terhadap Penyuluhan yang dilakukan Oleh Penyuluh.

\begin{tabular}{lclcc}
\hline No. & Responden & \multicolumn{1}{c}{ Kualitatif } & Kuantitatif & Persentase (\%) \\
\hline 1. & 40 & Sangat berkeinginan & 5 & 100 \\
2. & 0 & Berkeinginan & 4 & 0 \\
3. & 0 & Cukup berkeinginan & 3 & 0 \\
4. & 0 & Tidak berkeinginan & 2 & 0 \\
5. & 0 & Sangat tidak berkeinginan & 1 & 0 \\
\hline Jumlah & 40 & & & 100 \\
\hline
\end{tabular}

Indrayani, dan Andri, (2018.) menjelaskan bahwa Peran penyuluh dalam memotivasi peternak dalam beternak babi untuk kategori skor yaitu $82,5 \%$ yang memilih cukup baik, sementara itu $17,5 \%$ sangat baik. Hal ini menandakan bahwa penyuluh Dinas Pertanian Peternakan Dan Perkebunan Kabupaten Minahasa berpengaruh dalam memotivasi peternak. Hal tersebut bisa terjadi karena pembinaan kelompok peternak babi yang dilakukan oleh penyuluh dan juga memberikan arahan peningkatan produksi hasil yang dicapai dalam usaha ternak. Indikasi bahwa apabila produksi meningkat berarti pendapatan dan kesehjateraan peternak juga ikut meningkat. Hal ini yang diharapkan dari tujuan pembinaan kelompok peternak babi yang dilakukan oleh penyuluh dinas pertanian peternakan dan perkebunan kepada peternak. dapat dilihat pada. Tabel 4. Alimon, et al (2011) menjelaskan bahwa tingginya tingkat pendidikan responden disebabkan adanya kesadaran petani akan pentingnya pendidikan formal yang memudahkan penyuluh dalam memberikan materi penyuluhnya (Alimon, et al., 2011)
Selanjutnya dapat dilihat pada Tabel 5. menggambarkan bahwa tingkat pendidikan sangat baik terhadap pola pikir dalam beternak babi, hal ini dapat dilihat pada perolehan skor $62 \%$ yang menjawab baik dan $37 \%$ yang menjawab Cukup baik.

Hasil pada Tabel 6 menggambarkan bahwa penyuluh dinas Pertanian Peternakan Dan Perkebunan sangat memfasilitasi pembentukan kelompok peternak babi. Hal ini dapat dilihat pada perolehan skor yaitu $77 \%$ yang memilih memfasilitasi, $22 \%$ yang memilih sangat memfasilitasi. Data pada Tabel 7, menggambarkan bahwa semua peternak responden mendapatkan bibit ternak babi dari penyuluh Dinas Pertanian Peternakan Dan Perkebunan. Dalam hal ini peternak memperoleh bibit ternak babi 1 sampai 2 ekor per anggota kelompok peternak. Hal ini dapat dilihat pada perolehan skor $75 \%$ yang memilih baik dan $25 \%$ memilih cukup baik. Hal ini sejalan dengan Priyono et al. (2015) bahwa peternak memiliki pesepsi yang sangat baik dengan bantuan peternak berupa sarana produksi Tabel 4. Tanggapan Peternak terhadap Peran Penyuluh dalam Memotivasi Peternak Babi.

\begin{tabular}{lllcc}
\hline No. & Responden & Kualitatif & Kuantitatif & Persentase $(\%)$ \\
\hline 1. & 7 & Sangat baik & 5 & 17 \\
2. & 0 & Baik & 4 & 0 \\
3. & 33 & Cukup baik & 3 & 82 \\
4. & 0 & Kurang & 2 & 0 \\
5. & 0 & Tidak ada & 1 & 0 \\
\hline Jumlah 40 & & & 100 \\
\hline
\end{tabular}


Tabel 5. Tanggapan Peternak terhadap Peran Penyuluh dalam Mempengaruhi Pola Pikir Peternak.

\begin{tabular}{lllll}
\hline No. Responden & Kualitatif & Kuantitatif & Persentase (\%) \\
\hline 1. & 7 & Sangat baik & 5 & 0 \\
2. & 25 & Baik & 4 & 62 \\
3. & 15 & Cukup baik & 3 & 37 \\
4. & 0 & Kurang & 2 & 0 \\
5. & 0 & Tidak ada & 1 & 0 \\
\hline \multicolumn{2}{l}{ Jumlah 40} & & & 100 \\
\hline
\end{tabular}

Tabel 6. Tanggapan Peternak terhadap Peran Penyuluh dalam Memfasilitasi Pembentukan Kelompok Peternak Babi.

\begin{tabular}{lclcc}
\hline No. & Responden & \multicolumn{1}{l}{ Kualitatif } & Kuantitatif & Persentase (\%) \\
\hline 1. & 3 & Sangat memfasilitasi & 5 & 22 \\
2. & 31 & Memfasilitasi & 4 & 77 \\
3. & 0 & Cukup menfasilitasi & 3 & 3 \\
4. & 0 & Tidak memfasilitasi & 2 & 0 \\
5. & 0 & Sangat Tidak memfasilitas & 1 & 0 \\
\hline Jumlah & 40 & & & 100 \\
\hline
\end{tabular}

Tabel 7. Tanggapan Peternak terhadap Peran Penyuluh dalam Memberikan Bantuan Bibit Ternak Babi.

\begin{tabular}{lclcc}
\hline No & Responden & \multicolumn{1}{c}{ Kualitatif } & Kuantitatif & Persentase (\%) \\
\hline 1. & 0 & Sangat baik & 5 & 100 \\
2. & 30 & Baik & 4 & 75 \\
3. & 10 & Cukup baik & 3 & 25 \\
4. & 0 & Kurang baik & 2 & 0 \\
5. & 0 & Tidak baik & 1 & 0 \\
\hline Jumlah & 40 & & & 100 \\
\hline
\end{tabular}

Hasil pada Tabel 8. menjelaskan bahwa peternak setuju apabila penyuluhan dilakukan sekali sebulan. Hal ini dapat dilihat pada perolehan skor $100 \%$ yang menjawab sangat setuju yang sejalan dengan Alim (2010). Selanjutnya data pada Tabel 9 menunjukkan bahwa pendapatan peternak meningkat dengan adanya pembinaan dari penyuluh dinas peternakan. Hal ini dapat dilihat pada perolehan skor $42,5 \%$ yang menjawab meningkat dan $57,5 \%$ yang menjawab cukup meningkat. Tae-hun, et al. (2014.) mengatakan bahwa pendapatan peternak yang memperoleh pembinaan dari penyuluh mengenai jenis bibit yang baik ternyata mengalami peningkatan di bandingkan dengan peternak yang tidak diintervensi dengan penyuluhan Pada Tabel 10. menunjukkan bahwa $100 \%$ peternak yang memilih jawaban sangat menguntungkan setelah bergabung dalam kelompok peternak babi yang dibina oleh penyuluh dinas Pertanian peternakan di Desa Kamanga Kecamatan Tompaso Kabupaten Minahasa. Hal ini sejalan dengan Ali et al. (2011), bahwa kelompok sangat menguntungkan petani. 
Tabel 8. Tanggapan Peternak Terhadap Intensitas Yang Dilakukan Oleh Penyuluh.

\begin{tabular}{lclcc}
\hline No. & Responden & Kualitatif & Kuantitatif & Persentase ( \%) \\
\hline 1. & 40 & Sangat setuju & 5 & 100 \\
2. & 0 & Setuju & 4 & 0 \\
3. & 0 & Cukup setuju & 3 & 0 \\
4. & 0 & Tidak setuju & 2 & 0 \\
5. & 0 & Sangat Tidak setuju & 1 & 0 \\
\hline Jumlah & 40 & & 100 \\
\hline
\end{tabular}

Tabel 9. Tanggapan Peternak terhadap Peran Penyuluh dalam Meningkatkan Pendapatan Anggota Kelompok Peternak Babi.

\begin{tabular}{lclcc}
\hline No. & Responden & Kualitatif & Kuantitatif & Persentase (\%) \\
\hline 1. & 0 & Sangat meningkat & 5 & 0 \\
2. & 17 & Meningkat & 4 & 42 \\
3. & 23 & Cukup meningkat & 3 & 57 \\
4. & 0 & Tidak meningkat & 2 & 0 \\
5. & 0 & Sangat Tidak meningkat & 1 & 0 \\
\hline Jumlah & 40 & & & 100 \\
\hline
\end{tabular}

Tabel 10. Tanggapan Peternak terhadap Penyuluh tentang Manfaat yang diperoleh Setelah Bergabung dalam Kelompok Peternak Babi.

\begin{tabular}{lclcc}
\hline No. & Responden & \multicolumn{1}{c}{ Kualitatif } & Kuantitatif & Persentas (\%) \\
\hline 1. & 40 & Sangat menguntungkan & 5 & 100 \\
2. & 0 & Menguntingkan & 4 & 0 \\
3. & 0 & Cukup menguntungkan & 3 & 0 \\
4. & 0 & Tidak menguntngkan & 2 & 0 \\
5. & 0 & Sangat tidak menguntungkan & 1 & 0 \\
\hline Jumlah & 40 & & & 100 \\
\hline
\end{tabular}

Tabel 11. Tanggapan Peternak dalam Meningkatkan Skala Usaha Babi.

\begin{tabular}{lclcc}
\hline No. & Responden & Kualitatif & Kuantitatif & Persentase $(\%)$ \\
\hline 1. & 40 & Sangat berkeinginan & 5 & 100 \\
2. & 0 & Berkeinginan & 4 & 0 \\
3. & 0 & Cukup berkeinginan & 3 & 0 \\
4. & 0 & Tidak berkeinginan & 2 & 0 \\
5. & 0 & Sangat tidak berkeinginan & 1 & 0 \\
\hline Jumlah & 40 & & & 100 \\
\hline
\end{tabular}

Peranan yang sangat besar dalam peningkatan Pada Tabel 11. menggambarkan bahwa keseluruhan peternak responden atau $100 \%$ sangat berkeinginan meningkatkan skala usaha beternak babi mereka. Hal ini dimaksudkan agar pendapatan para peternak bisa lebih meningkat lagi. Osak, et al. (2018) menjelaskan bahwa hasil yang diperoleh tentang tanggapan atau respon peternak terhadap pembinaan kelompok peternak babi menggambarkan bahwa, kerjasama antara 
penyuluh dinas Pertanian Peternakan Dan Perkebunan sebagai motivator, pendamping dan fasilitator dalam memberikan bantuan, materi dan arahan terjalin kerjasama yang baik dengan peternak sebagai penerima program pembinaan kelompok peternak babi. Bahua, et al. (2013.) mengatakan bahwa hal hal yang dikembangkan penyuluh Dinas Pertanian Peternakan Dan Perkebunan mendapat respon yang baik dari peternak. Oleh karena itu, peternak mendapatkan manfaat yang besar baik dari segi pengetahuan, wawasan, perubahan perilaku untuk lebih maju dan berkembang dalam menerima inovasi khususnya perubahan teknologi peternakan. Manfaat yang juga diperoleh peternak yaitu dapat mengalami peningkatan pendapatan yang lebih baik.. Hal tersebut bisa terjadi karena pembinaan kelompok peternak babi yang dilakukan oleh penyuluh Dinas Pertanian Peternakan Dan Perkebunan juga memberikan peningkatan produksi hasil yang dicapai dalam setiap usaha ternak. Indikasi bahwa apabila produksi meningkat berarti pendapatan dan kesehjateraan peternak juga ikut meningkat.Hal ini yang diharapkan dari pembinaan kelompok peternak. (Muhammad, et al., 2014.).

\section{KESIMPULAN}

Penyuluh dari dinas pertanian peternakan dan perkebunan memiliki peran terhadap anggota kelompok peternak babi di Desa Kamanga Kecamatan Tompaso Kabupaten Minahasa. Program pembinaan kelompok peternak babi yang dikembangkan penyuluh dari dinas pertanian peternakan dan perkebunan mendapat respon yang baik dari peternak. Oleh karena itu, peternak mendapatkan manfaat yang besar baik dari segi pengetahuan, wawasan, perubahan perilaku untuk lebih maju dan berkembang dalam menerima inovasi khususnya perubahan teknologi peternakan. Penyulkuh telah berperan dengan baik dalam meningkatkan pendapatan peternak babi di Kecamatan Tompaso Barat Kabupaten Minahasa.

\section{DAFTAR PUSTAKA}

Abdullah, A. dan H. Ibrahim, 2014. Persepsi peternak terhadap kinerja penyuluh dalam pengembangan teknologi pengolahan jerami padi dan limbah ternak Babi. Jitro 1(1):100

Ali O,A.M., N.J. Kathuri and T.E.O.Wesonga. 2011. Effective extension methods for increased food production in kakamega district., Kenya: EgertonUniversity.Journal Of Agricultural Extension And Rural Development. 3(5):95-101.

Alim, S. 2010. Bahan Ajar Penyuluhan Pertanian (Peternakan).

Laboratorium Sosiologi dan Penyuluhan. Fakultas Peternakan Universitas Padjajaran, Bandung.

Alimon, Susanto A, Sodiq A, Indrasanti D, Haryoko I, Ismoyowati, Sumarmono J, Muatip dan K. Iriyamti. 2011. Prospek dan potensi sumberdaya ternak local dalam menunjang ketahanan pangan hewani. Prosiding seminar nasional Unsoed 15 Oktober 2011. Purwokerto, Unsoed Press Hal. 266-270

Anwas, O.M. 2013. Pengaruh pendidikan formal pelatihan dan intensitas pertemuan terhadap kompetensi penyuluh pertanian. Jurnal Pendidikan dan Kebudayaan. 19(1):50-62.

Astuti, M. 2011. Jurnal Analisa Keuntungan Sistem Pertanian Terpadu Berbasis Holtikultura Pada Kelompok Tani Bumi harapan Di Nagari Koto Tinggi Kecamatan Baso Kabupaten Agam [Skripsi]. Padang: Fakultas Pertanian Universitas Andalas.

Chamdi AN. 2011. Jurnal Karakteristik 
sumberdaya genetik ternak babi Bali (Bos-bibos banteng) dan alternatif pola konservasinya. Biodiversitas. 6:70-75.

Dali, I., F.S Oley, A. K. Rintjap, dan J. M Tumewu. 2017. Hubungan kinerja penyuluh pertanian lapangan dengan keberhasilan peternak Babi di Kecamatan Kwandang Kabupaten Gorontalo Utara. Jurnal Zootek 37(2):403-414.

Ditjen Peternakan. 2010. Rencana Strategis Sub Sektor Peternakan Indonesia Tahun 2010-2014. Departemen Pertanian RI, Jakarta.

Harinta, Y.W., 2011. Adopsi inovasi pertanian di kalangan petani di Kecamatan Gatak

Kabupaten Sukoharjo. Jurnal Agribisnis 15(2):164-174.

Indrayani, I. dan Andri, 2018. Faktor-faktor yang mempengaruhi pendapatan usaha ternak babi di Kecamatan Sitiung, Kabupaten Dharmasraya. Jurnal Peternakan Indonesia 20(3):151-159.

Ikbal, M. 2014. Peranan Kelompok Tani dalam Meningkatkan Pendapatan Petani Padi Sawah di Desa Margamulya Kecamatan Bungku Barat Kabupaten Morowali. e-J. Agrotekbis, 15(2):505-509.

Iriyanti. 2011 Prospek dan potensi sumberdaya ternak lokal dalam menunjang Ketahanan Pangan Hewani. Prosiding Seminar Nasional. Purwokerto, 15 Oktober 2011. Purwokerto (Indonesia): UNSOED press. hlm. 266-270

Mandasari, S. 2014. Hubungan Peran Kelompok Tani dengan Produktivitas Usahatani Benih Padi (Studi Kasus: Kelompok Tani Surya Bangkit di Desa Mandalawangi. Kecamatan Sukasari. Kabupaten Subang .Skripsi. Program Studi Agribisnis
Fakultas Sains Dan Teknologi Universitas Islam Negeri Syarif Hidayatullah

Mutmainah, R., dan Sumardjo. 2014. Peran Kepemimpinan Kelompok Tani dan Efektivitas Pemberdayaan Petani. Jurnal Sosiologi Pedesaan, 19(1):182-199.

Muhammad, S.D.S., R.A.J. Legrans, E. Wantasen dan J. Lainawa, 2014. Hubungan antara faktor sosial ekonomi dengan persepsi peternak terhadap pengembangan peternakan babi di Kota Tomohon. Jurnal Zootek 34(2):39-48

Nurfitri, E. 2018. Sistem Pemeliharaan dan Produktivitas babi pada Berbagai Kelas. Kelompok Peternak di Kabupaten Ciamis. Skripsi. Fakultas Peternakan, Institut Pertanian, Bogor.

Osak, R.E.M.F., T.F.D. Lumy and M.L Rundengan, 2018. Application of environmentally friendly technology to dairy farming in South Tomohon Subdistrict, North Sulawesi, Indonesia. International Journal of Engineering Inventions 7(4):16-18.

Priyono, M.I., D. Shiddieqy, Widiyantono dan Zulfanita. 2015. Hubungan kausal antara tingkat penguasaan teknologi, dukungan kelembagaan dan peran penyuluhan terhadap adopsi integrasi ternak. Jurnal Informatika Pertanian. 24(2):141148.

Sapar.,A. Jahi,P.S. Asngari, Amiruddin dan I.G.P. Purnaba. 2012. Kinerja penyuluh pertanian dan dampaknya pada kompetensi petani kakao di empat wilayah Sulawesi Selatan. . Jurnal Penyuluhan.8(1):29-41.

Sampurna, I.P., I.K. Suatha, dan Z. Menia,2011. Pola pertumbuhan dimensipanjang dan lingkar tubuh 
babi landrace. Majalah Ilmiah Peternakan 14(1):18-21.

Sudarsono, A., dan Y Suharsono, 2016 Hubungan persepsi terhadap kesehatan dengan kesadaran (mindfulness) menyetor sampah anggota klinik asuransi sampah di Indonesia. Jurnal Ilmiah Psikologi Terapan 4(1):31-52.

Tae-hun K., N. Markov and I Seryodkin. 2014. Genetic structure of wild boSaurs (scrofa) populations from East Asia based on microsatellite loci analyses. BMC Genet. 15:1-10
Talibo, R., B. F. J. Sondakh, A. A. Sajow dan J. Lainawa, 2017. Analisis persepsi petani peternak babi terhadap peran penyuluh di Kecamatan Sangkub Kabupaten Bolaang Mongondow Utara. Jurnal Zootek 37 (2) : 513-525 